\title{
Competition between biofuels: Modeling technological learning and cost reductions over time
}

\author{
Marc de Wit ${ }^{a, *}$, Martin Junginger ${ }^{a}$, Sander Lensink ${ }^{b}$, Marc Londo $^{b}$, André Faaij $^{a}$ \\ ${ }^{a}$ Department of Science, Technology and Society, Copernicus Institute for Sustainable Development and Innovation, Utrecht University, \\ Heidelberglaan 2, 3584 CS Utrecht, The Netherlands \\ ${ }^{\mathrm{b}}$ Energy research Centre of the Netherlands (ECN), Unit Policy Studies, Westerduinweg 3, 1755 ZG, Petten, The Netherlands
}

\section{A R T I C L E I N F O}

Article history:

Received 9 January 2009

Received in revised form

20 May 2009

Accepted 9 July 2009

Published online

\section{Keywords:}

Technological learning

Advanced biofuels

Experience curves

Modeling

Biofuel competition

\begin{abstract}
A B S T R A C T
A key aspect in modeling the (future) competition between biofuels is the way in which production cost developments are computed. The objective of this study was threefold: (i) to construct a (endogenous) relation between cost development and cumulative production (ii) to implement technological learning based on both engineering study insights and an experience curve approach, and (iii) to investigate the impact of different technological learning assumptions on the market diffusion patterns of different biofuels. The analysis was executed with the European biofuel model BioTrans, which computes the least cost biofuel route. The model meets an increasing demand, reaching a $25 \%$ share of biofuels of the overall European transport fuel demand by 2030. Results show that 1st generation biodiesel is the most cost competitive fuel, dominating the early market. With increasing demand, modestly productive oilseed crops become more expensive rapidly, providing opportunities for advanced biofuels to enter the market. While biodiesel supply typically remains steady until 2030, almost all additional yearly demands are delivered by advanced biofuels, supplying up to $60 \%$ of the market by 2030 . Sensitivity analysis shows that (i) overall increasing investment costs favour biodiesel production, (ii) separate gasoline and diesel subtargets may diversify feedstock production and technology implementation, thus limiting the risk of failure and preventing lock-in and (iii) the moment of an advanced technology's commercial market introduction determines, to a large degree, its future chances for increasing market share.
\end{abstract}

(c) 2009 Elsevier Ltd. All rights reserved.

\section{Introduction}

Driven by general sustainable energy targets and specific biofuel targets to curb green house gas (GHG) emissions, concerns regarding security of supply and especially in recent years rising oil prices, the production and use of biofuels have been steadily increasing globally in the last decades. The EU encourages developments to achieve an ambitious 10\% share of biofuels by 2020 [1]. Driven by this target the demand for biofuels in Europe can be expected to face a strong increase compared to the current (2007) 2.6\% [2]. With such turbulent short-term development comes the need for an integrated long-term vision for biofuels, as set in the REFUEL project [3]. Amongst other aspects, the role of technological learning (and associated cost reductions) is a crucial factor affecting the possible market diffusion of various 1st and 2nd generation biofuels.

Given the complex interactions between the various biofuels and fossil transportation fuels, the use of models for biofuel market penetration can be a useful tool for policy

\footnotetext{
* Corresponding author. Tel.: +31 30253 7610; fax: +31 302537601.

E-mail address: m.p.dewit@uu.nl (M. de Wit).
}

0961-9534/\$ - see front matter ( 2009 Elsevier Ltd. All rights reserved. doi:10.1016/j.biombioe.2009.07.012 


Nomenclature
FT $\quad$ Fischer-Tropsch synthetic diesel
LE $\quad$ lignocellulose ethanol
DME $\quad$ dimethylether
SNG $\quad$ substitute natural gas
WEC $\quad$ Western European Countries
CEEC $\quad$ Central and Eastern European Countries
Conversion factors
tonne $\quad 1.0 \mathrm{Mg}^{\text {31.71 GW }} 1.0 \mathrm{EJ} \mathrm{y}^{-1}$

makers, market actors and scientists. The use of energy models is not new - a wide variety of energy models have been constructed to provide policy makers with a better insight into the complexities of energy system development under various policy objectives. Many describe the complete energy system either with a technical 'bottom-up' (systems engineering) approach or with a macro-economic 'top-down' approach [4]. Specifically regarding the market penetration of biofuels, a limited number of models exist, e.g. the ESIM and LEITAP models [5], the BioTrans model [6] (used in this study) for Europe or the biodiesel model [7] for the US.

A crucial aspect of these models is how technological learning and subsequent cost reductions over time are taken into account, as these can drastically change the economic competitiveness and thus market share of a biofuel compared to other (fossil and renewable) fuels. Some energy models tend to define future cost levels ex ante, i.e. cost reductions are independent of market developments. This approach ignores demand driven market dynamics and the notion that technological learning (and subsequent cost reductions) depend on the degree to which a technology is utilized; a phenomenon which has been observed numerous times, and that can be quantified using the experience curve approach. For this reason, endogenous learning has increasingly been incorporated in many energy models but this has not been attempted for models specifically focusing on biofuels for transport.

Analysis for this study is executed with the BioTrans model, which assesses the European biofuel mix that establishes given a target-driven biofuel demand. The model fills-in the yearly demand by computing the least cost biofuel mix. The development of production cost can be modeled endogenously which makes BioTrans particularly suitable to assess the influence of specific learning parameter values on competition between fuels over time.

The objective of this study is threefold, it aims to

(i) Construct the (endogenous) relation between cumulative installed capacity and associated production cost reductions, or if this is not possible construct an (exogenous) relation following a hybrid approach, in which insights from engineering studies (mainly regarding scale effects) are combined with a scale-independent experience curve approach for both 1st and 2nd generation feedstocks and 1st and 2nd generation biomass-to-biofuel conversion technologies,

(ii) implement these relations in the BioTrans model and

(iii) illustrate the consequences of these assumptions on the rate of technological learning, its effect on market diffusion and determine the future biofuel mix as a result of the market competition.

\section{Methodology \\ 2.1. Technological learning and cost reductions in feedstock production}

Feedstock production costs can reduce over time, mainly by gaining experience with its production. The lack of historical production cost data prohibits the possibility to model cost developments endogenously. In principle, however, feedstock production costs can be modeled endogenously, i.e. relating annual production volumes (as a proxy for gained experience) to decreasing production costs. Analyses performed for sugarcane in Brazil [8], for corn in the US [9] and for rapeseed in Germany [10] demonstrated that indeed cost reductions of (food) crops do follow an experience curve pattern. Unfortunately, for all (other) crops considered in the study, no such studies are available which could provide the necessary time series and trend lines. However, the studies mentioned show that an increase in productivity is the single-most important driver for decreasing production costs for feedstocks, contributing between $65 \%$ and $85 \%$ to total cost decline, therefore making it a suitable parameter for estimating future cost reduction potentials. Increased productivity is an important measure for cost reduction as it shows the results of improving management (e.g. adequate pest control, optimized fertilizer application etc.). Another aspect contributing to reducing costs is economies of scale in transportation, e.g. the use of larger trucks, trains or ships [8].

The productivity increase of agricultural commodity crops was modeled on the basis of a fixed annual increase, with the annual increment being developed from a time series analysis of the specific crop [11]. Despite there being a physical limit to this approach over a long duration, this trend is amply confirmed for Europe over the last four decades [12,13]. An equation

$\mathrm{Y}_{\mathrm{e}}=f_{\mathrm{Y}} \cdot \mathrm{t}_{\mathrm{y}}+b$

was fitted to the historical data. The relative yield improvement $\left(\% \mathrm{y}^{-1}\right)$ decreases over time as shown in Fig. 1 . We have equated yield improvement rate to be the same as the production cost decrease during the period of our analysis from 2005 to 2030 with the initial crop production costs taken from [14].

Lignocellulosic crop productivity development curves are generally unavailable except for some experimental tree crops such as Poplar, Willow and Eucalyptus $[15,16]$ and herbaceous species such as Miscanthus and Switchgrass $[17,18]$. Instead of fitting a curve to empirical data, literature data $[19,20]$ have been used to project the maximum productivity (and thus cost reductions) for 2030 .

\subsection{Technological learning and cost reductions for conversion technologies}

An experience (or learning) curve, as this empirical causality relation is often referred to, expresses the cost decline by 
Relative yield improvement as a proxy for production cost reduction, in \% per annum

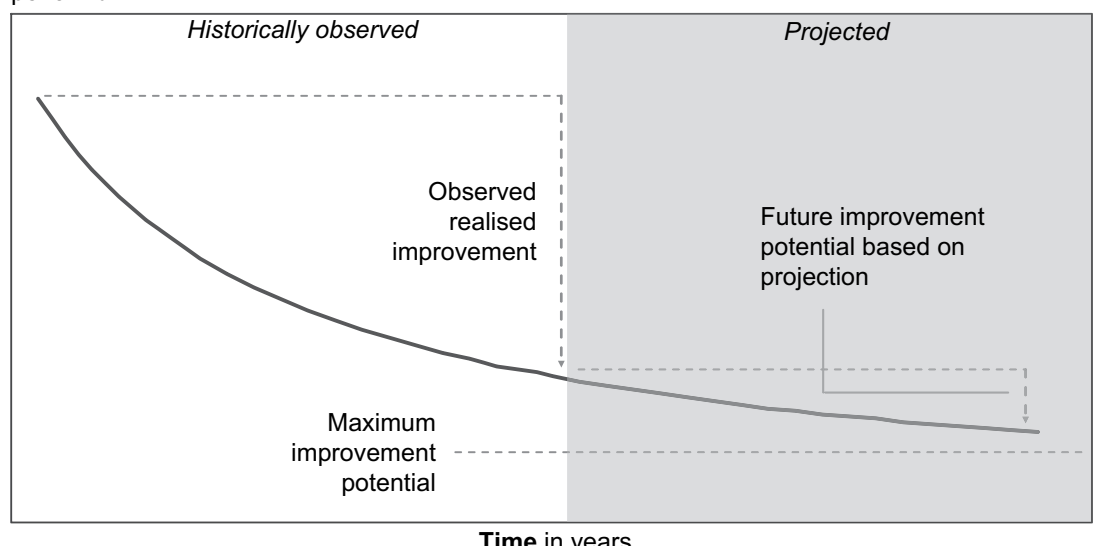

Fig. 1 - Production costs improvement potential over time.

a constant factor with each doubling of cumulative number of units (or capacity) produced or installed [21]. This relation can be written as:

Cost $_{\text {cum }}=$ Cost $_{0} \cdot$ production $_{\text {cum }}^{b}$

$\mathrm{PR}=2^{b}$

Future production costs ( Cost $\left._{\text {cum }}\right)$ can be projected with the experience curve (Eq. (3)) if the costs (Cost ${ }_{0}$ ) are known at the start of production and the cumulative (unit) production (production $_{\text {cum }}$ ) at a future moment in time. The progress ratio $(\mathrm{PR})$ is a parameter that can be derived from the experience index (Eq. (4)), that expresses the rate at which costs decline for every doubling of cumulative production. For example, a progress ratio of $80 \%$ equals a $20 \%$ cost decrease for each doubling of the cumulative capacity. Production cost decrease over time due to improvements in the process (incremental innovations), scaling up of individual units, experience gained by operation and maintenance etc. [22]. The use of experience curves for estimation of the progress ratio is often used for analysis of (historic) cost data coupled to (cumulative) production figures. Based on production cost developments over cumulative production, progress ratios have been derived for a multitude of energy technologies, including biomass combustion and biomass anaerobic digestion technologies [22] and 1st generation biofuel conversion technologies [8-10]. A meta-overview of these data and progress ratios, based on (bottom-up) studies, is presented in Section 3.2. These data are applied in the BioTrans model to endogenously model cost development of 1st generation conversion as a function of cumulative produced biofuels.

However, for 2 nd generation biofuel plants, the problem of data availability arises. Currently, only experimental-scale and pilot plants for both FT and LE production exist. First commercial units are expected to go online in the next few years $[23,24]$. Consequently, it is not possible to empirically determine progress ratios for 2 nd generation biofuel conversion technologies. A solution to this could be to take a 'best guess' progress ratio. But as the progress ratio is often one of the most sensitive parameters for model outcomes, this was not deemed an option. A more refined possibility would be to estimate progress ratios for separate component of a biofuel plant, as done earlier for example for Biomass Integrated Gasification Combined Cycle plants $[25,26]$. Still, this method relies on expert judgments to estimate progress ratios.

Therefore, for this study, a hybrid approach was developed, in which insights from engineering studies (mainly regarding scale effects) were combined with a scale-independent experience curve approach. Both are described in more detail below.

\subsubsection{Scale-dependant learning}

A widely applied concept in engineering studies is the use of scaling laws. The scale learning approach describes a relation between increases in plant scale and associated decreasing production costs, according to a scale law $[27,28]$ which can be written as:

$\frac{\text { Cost }_{\mathrm{P} 2}}{\text { Cost }_{\mathrm{P} 1}}=\left(\frac{\text { Scale }_{\mathrm{P} 2}}{\text { Scale }_{\mathrm{P} 1}}\right)^{R}$

The capital cost for a process configuration Cost $_{P 2}$ is determined by the current cost of the installation Cost $_{P 1}$ and by the ratio of the future scale and the current scale to the magnitude of the scale factor $R$, following Eq. (4). Future cost can be estimated by applying an empirical determined or theoretically derived scale factor. Typically, empirically determined scale factors vary between 0.6 and 0.9. Note that for many plant components maximum sizes exist, which dampen or even stall the reduction of costs with increasing scales. Also, for (biomass) plants, larger plant sizes require larger amounts of feedstock, typically increasing average feedstock costs. Thus, conversion plants have an optimum scale at which specific fuel production costs are minimal [29].

As engineering studies have been published for 2nd generation biofuels which specify the (expected) scale effects, it is possible to integrate the scale effect into BioTrans. To incorporate scaling in the model, three boundary conditions had to be included: 


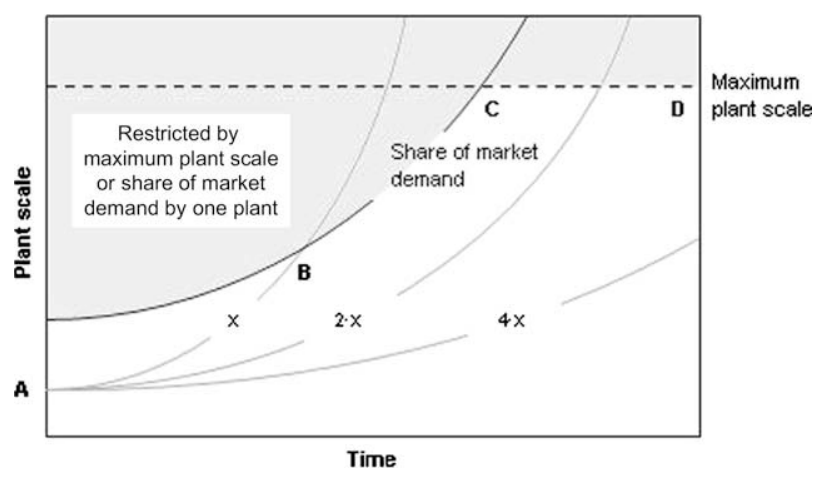

Fig. 2 - Schematic overview of the doubling-time approach with two restrictions (maximum scale and maximum market share).

(i) First, there is a maximum speed with which technologies can be scaled-up. This is primarily related to technological learning-larger plants often display new problems, which have to be solved before further scaling can take place. Another requirement is a growing market, which allows producers to increase production by building a bigger plant (or by operating facilities, with a similar or smaller scale, in series). This phenomenon has been observed for many energy technologies [30] e.g. natural gas turbines [31], wind turbines [32] and fluidized bed boilers [33]. Typical doubling times for these technologies are 3-5 years.

(ii) Second, as argued above, an absolute maximum plant size is postulated:

(iii) Third, a restriction is introduced that a single plant cannot supply more biofuels than a fixed percentage of the total market capacity (e.g. 5\%) at any given moment. This restriction is necessary to prevent that in the model runs, a single plant could supply unrealistic high shares of the market. These limitations can be modeled using Eq. (5)

Scale $_{t}=$ Scale $_{0} \cdot e^{\left(\frac{L N(2)}{\text { doublingtime }} \cdot t\right)}$

with Scale $\mathrm{t}_{\mathrm{t}} \leq$ Scale $_{\max }$ and Scale $\mathrm{t} \leq x \% \cdot$ MarketCapacity.

Fig. 2 illustrates the consequences of these limitations, following the line segments indicated with letter symbols. Section A-B is the potential scale-up until limited by the maximum market share supplied by a single plant. Section $\mathrm{B}-\mathrm{C}$ is the assumed market growth rate with the plant scale following $5 \%$ of the market share. The plateau, from C to D, represents the physical limiting scale for the plant considered. At slower up-scaling $(2 \times$ and $4 \times$ ) it is more likely that the physical limit limits plant scale rather than the growth rate of the market.

\subsubsection{Scale-independent learning}

In addition to scale-dependant cost projections, additional reductions can occur through technological process improvements which are not related to scale. Examples are increased efficiency, lifetime prolongation of catalysts, the use of advanced materials etc. Scale-independent learning has reduced the costs of ethanol production from corn [9], and sugarcane $[8,34]$ by $25-50 \%$. These scale-independent cost reductions where related to the cumulative volumes of ethanol produced. Thus it was possible to derive experience curves (and PRs) for scale-independent learning. Due to the lack of any more adequate data, the PR-ranges of the 1st generation biofuels technologies were used in Biotrans to model scale-independent cost reductions of the 2 nd generation technologies.

\section{Data input}

\subsection{The BioTrans model}

The BioTrans model is utilized for optimizing full supply chain allocation. In the fuel supply chain, BioTrans considers four steps (i) feedstock production, (ii) biomass-to-biofuel conversion, (iii) fuel distribution and (iv) end-use. The transport costs are dependant on transport distance, the distribution of fuels and expenses for end-use is considered fixed and only fuel dependant [6]. Due to lower average density and hygroscopic characteristics additional costs for bioethanol and biodiesel compared to fossil equivalent fuels are respectively 0.88 and $0.12 € \mathrm{GJ}^{-1}$. The cost for feedstock production and the conversion of feedstocks to fuel change over time, as a result of cumulative produced volumes. The model essentially aims at finding the minimal cost allocations along the supply chain given projections of demand (e.g. based on biofuel policy targets), potentials and technological progress. Between the different steps in the supply chain, trade is possible between member states. The model uses as input a wide range of (mainly techno-economic) parameters regarding the current European biofuel situation, as well as macro-economic and technological projections. The output of the BioTrans model includes detailed allocations of production, processing, transport and distribution of energy crops and biofuels.

Biotrans can model 1st generation fuels (biodiesel based on vegetable oil crops and used fats, and ethanol based on sugar and starch crops) and a number of 2nd generation fuels: Fischer-Tropsch diesel (FT) and DiMethylEther (DME) through gasification, substitute natural gas (SNG) through either gasification \& methanation or anaerobic digestion and lignocellulose ethanol (LE) through fermentation. Note that, at least for the European situation 1st generation biofuels are generally produced from expensive feedstocks in established and optimized technologies, while the 2 nd generation is expected to use relatively lower cost feedstocks and what are presently capital intensive multistep process technologies.

The synthesis paper in this volume [3] develops three biofuel target scenarios. Of the three developed scenarios the high target scenario is used in this study. The demand for biofuels as a share of overall transport fuels develops as follows: $5.75 \%$ by 2010, 14\% by 2020, and $25 \%$ by 2030 .

\subsection{Feedstock production cost development}

\subsubsection{Oil, starch and sugar crops}

Time series data on the productivity development of crops are used for the period 1961-2005 [35]. The data are available for country level aggregates, taken for 30 European countries 
(EU27, Norway, Switzerland and Ukraine). Crops included in this study are rapeseed, sunflower (seed), sugar beet, wheat, rye and corn.

For this analysis, developments are described on a national level and for the larger regions of the Western European Countries (WEC) and the Central and Eastern European Countries (CEEC). Rationale for the division between WEC and CEEC is that developments in the agricultural sectors between these two regions have been significantly different, while developments within these regions have been relatively comparable. The WEC have for the last decades made great progress in increasing its agricultural productivity by modernization and up-scaling. Much of these developments have been made possible by a EU focus on and funding for the agriculture sector. The CEEC have dominantly been under centrally planned agricultural policy which initially did raise agricultural output. In the transition to market economies around the 1990s, however, production fell sharply. Distinct differences in these developments have led to considerable differences to the current day with respect to cost levels, mainly for land and labour, affecting crop production costs.

\subsection{2. (Herbaceous) lignocellulose crops}

Production costs to date have been relatively high, mostly because their production is geographically spread-out and typically small-scale. Estimates on the potential to reduce production costs for (herbaceous) lignocellulose crops vary from $9 \%$ on average for Switchgrass [36], 19\% for willow in Sweden [20] and 35\% on average for lignocellulose crops [19]. All references state preconditions that have to be met in order to reach the estimated cost reductions, such as upscaling of production, improved and extended machinery use, breeding optimization, improved management through more adequate crop-specific knowledge. Barriers are formed by the limited size of farms, geographical fragmentation etc. [19]. Furthermore, the production costs for the base year (2005) are taken from results presented elsewhere in this volume [14].

\subsection{Biomass-to-biofuel conversion cost development}

All data presented are in 2004 euros. Where necessary data provided in different currencies (e.g. US\$) have been converted to euros using the average exchange rate in the year of the publication of the data source. No attempt was made to correct for inflation for the period 2000-2004.

\subsubsection{Vegetable oil to biodiesel}

Three process steps are considered to produce biodiesel (i) oil extraction, (ii) transesterification of virgin oils from oil seeds for the two-step process of biodiesel production - and (iii) transesterification of used oils and fats for biodiesel production from residue streams. Pure vegetable oil is produced from oil seeds (e.g. rapeseed or sunflower) by mechanical pressing or solvent extraction. Used fats and oils can be obtained e.g. from slaughterhouse waste and frying and cooking oil. Biodiesel can, subsequently, be produced from either the obtained pure vegetable oil or used fats and oils by a transesterification process. This technology is long since used and is applied specifically for biodiesel production in Europe (most notably in Germany) since the early 1990s. Data on investment and operation costs are based on various sources $[37,38]$, see Table 2.

For the estimation of the technological learning, the transesterification process for biodiesel from oil crops and from used fats and oils were taken as one entity. For both technologies typical (large) scale installations (Table 2) were considered following [10]. An endogenous learning progress ratio for biodiesel production from pure vegetable oil is estimated in the range of $90 \%$ (Table 3 ). The cumulative production volume of biodiesel in the EU25, up to and including 2004, is compiled from data available for the EU15 from 1993 and for the CEEC from 2002 [39].

\subsubsection{Sugar and starch to ethanol}

Production of ethanol from sugar and starch comprises of two major process steps (i) the production of sugar and (ii) the fermentation of sugar to ethanol. Production of sugar from sugar crops (e.g. sugar beet) involves crushing, and extraction of the sugar. Production of sugar from starch crops (e.g. wheat) involves milling of the grains to obtain the starchy material, dilution and heating to dissolve the starch and conversion of the starch to sugars by hydrolysis. The data for investment and operation costs for conventional bioethanol production, from sugar and starch crops $[40,41]$ are presented in Table 2.

For technological learning, the ethanol process from sugar crops and the one from starch crops were taken as one process (entity). The progress ratio for bioethanol was estimated at $80 \%$, based on the experience of learning in bioethanol production in Brazil [8] and the US [9]. For estimation of the cumulative production volume, all ethanol produced in Europe from sugar and starch is considered, instead of only that for fuel purposes. The rationale for this is that the fermentation process learns from both the production of ethanol for fuel and ethanol for other purposes. Production data were obtained for the 1970-2000 period [42] and for the 2001-2004 period [39,43]. Based on the 1970-2004 period production volumes were extrapolated back to 1950. For this (re)constructed historic time period, cumulative production up to and including 2004-in Europe amounts to almost $1.35 \mathrm{EJ}$ (see Table 3).

\subsubsection{Lignocellulose to ethanol}

Process description - Production of bioethanol from lignocellulose (LE) material comprises of three major steps (i) pretreatment of the lignocellulose material, (ii) hydrolysis of the lignocellulose to break it down into sugars (C5 and C6-sugars) and (iii) fermentation of the sugars to convert it into bioethanol. Various processes are available to pre-treat lignocellulose feedstocks [44] that are required to reduce size and improve surface-to-volume ratio to make it suitable for hydrolysis. Different levels of process integration, of the hydrolysis and fermentation processes, are possible that could reduce the number of reactors needed and so reduce associated installation costs, reduce process duration and raise overall process efficiency [34]. Data used in this study are based on a Simultaneous Saccharification and Fermentation (SFF) configuration, which was already considered stateof-the-art in 1996 [45,46], although this is also disputed [47]. 
Table 1 - Yield improvements and production costs for the period 2005-2030 for five crop groups.

\begin{tabular}{|c|c|c|c|c|c|c|}
\hline \multirow[t]{2}{*}{ Crop group/type } & \multirow[t]{2}{*}{ Region } & \multicolumn{3}{|c|}{ Productivity } & \multicolumn{2}{|c|}{ Production cost } \\
\hline & & $\begin{array}{l}\text { Estimated Yield } \\
2004^{\mathrm{d}} \mathrm{tha}^{-1} \mathrm{y}^{-1}\end{array}$ & $\begin{array}{l}\text { Projected } \\
\text { Yield } 2030^{e}\end{array}$ & $\begin{array}{l}\text { Improvement } \\
2004-2030 \%\end{array}$ & $\begin{array}{l}\text { Production costs } \\
2005^{\mathrm{C}} € \mathrm{GJ}^{-1}\end{array}$ & $\begin{array}{l}\text { Production } \\
\text { costs } 2030\end{array}$ \\
\hline \multicolumn{7}{|l|}{$\begin{array}{l}\text { Annual first generation crops }{ }^{a} \\
\text { Oil crops }\end{array}$} \\
\hline \multirow{2}{*}{ Rapeseed } & WEC & 2.6 & 3.0 & 14.6 & 10.30 & 8.80 \\
\hline & CEEC & 1.9 & 2.2 & 16.4 & 5.53 & 4.62 \\
\hline \multirow[t]{2}{*}{ Sunflower } & WEC & 1.9 & 2.2 & 14.9 & 10.30 & 8.77 \\
\hline & CEEC & 1.9 & 2.4 & 19.1 & 5.53 & 4.47 \\
\hline \multicolumn{7}{|l|}{ Starch crops } \\
\hline \multirow{2}{*}{ Wheat } & WEC & 5.9 & 7.9 & 25.7 & 9.05 & 6.72 \\
\hline & CEEC & 3.9 & 4.9 & 20.4 & 5.27 & 4.19 \\
\hline \multirow[t]{2}{*}{ Corn } & WEC & 9.0 & 12.8 & 30.3 & 9.05 & 6.31 \\
\hline & CEEC & 5.6 & 7.2 & 22.9 & 5.27 & 4.06 \\
\hline \multicolumn{7}{|l|}{ Sugar crops } \\
\hline \multirow[t]{2}{*}{ Sugar beet } & WEC & 5.8 & 7.3 & 20.7 & 5.32 & 4.22 \\
\hline & CEEC & 3.3 & 3.7 & 12.3 & 3.66 & 3.21 \\
\hline \multicolumn{7}{|l|}{ Perenial second generation crops ${ }^{b}$} \\
\hline \multirow[t]{2}{*}{ Lignocellulose crops } & WEC & 8 & 13 & $20-35$ & 3.38 & 2.45 \\
\hline & CEEC & 8 & 13 & $20-35$ & 1.66 & 1.20 \\
\hline \multirow[t]{2}{*}{ Herbaceous lignocellulose $\mathrm{crops}^{\mathrm{f}}$} & WEC & $10-20$ & $10-20$ & $20-35$ & 4.46 & 3.23 \\
\hline & CEEC & $10-20$ & $10-20$ & $20-35$ & 2.74 & 1.99 \\
\hline \multicolumn{7}{|c|}{$\begin{array}{l}\text { a Based on time series data FAOSTAT. } \\
\text { b Based on [18, 58-61]. } \\
\text { c Based on calculations for crop group averages [14]. } \\
\text { d The yield level for } 2004 \text { is the calculated yield based on the estimated yield development function obtained by linear fitting the historic yield } \\
\text { data for the period } 1961-2004 \text {. For many countries time series data were incomplete for the assessed 1961-2004 period. } \\
\text { e The yield level for } 2030 \text { is the result of extrapolation of the yield estimated function fitted for historic observed yields for the 1961-2004 period } \\
\text { as described under. } \\
\text { f } 2004 \text { yield level estimations for Miscanthus and Switchgrass in oven dry tonnes (odt ha }{ }^{-1} \mathrm{y}^{-1} \text { ) based on [36]. }\end{array}$} \\
\hline
\end{tabular}

Investment and O\&M costs - Capital and operation costs are based on a bottom-up engineering study $[48,49]$. Other factors such as process efficiency and excess electricity output, potentially available to deliver to the grid, are based on [34,49], see Table 2 . Based on the production costs that follow from the investment costs a scale-dependant cost development was estimated. A scale factor of 0.7 was used to calculate production costs at different scales. The assumed doubling time for both technologies is set at 5 years. The speed of up-scaling can be restricted, either by the market share one single plant can serve or if a maximum scale is reached (Table 2). The maximum scale was set rather modest (e.g. compared to a 'conventional' oil refinery scale) as larger plants would barely reduce specific investment costs further, while the required biomass logistics and storage would become increasingly complex.

Scale-independent technological improvement and cost reduction prospects - A key challenge is the ability to (efficiently and) cost competitively ferment pentose (C5) sugars [45]. Research and development efforts are directed at genetically engineering bacteria to meet these requirements, reports on its progress to date vary [50]. Pre-treatment, a process step to size the lignocellulose feedstock to make it susceptible to enzyme attack [20] is currently both capital and energy intensive. Future requirements to particle size may be relaxed due to improved hydrolysis thereby reducing energy and cost consumption and, consequently, improving performance [34]. More efficient (re)use of solvents can reduce expenses. Different levels of system integration of the hydrolysis and fermentation process can reduce system size, process duration, increase overall process efficiency and consequently improve cost performance.

Estimates for the cost learning potential are based on a process-step specific overview [20]. Estimated cost reduction potential for the processes are: pre-treatment (33\%), SSF fermentation (28\%), distillation (13\%), Other processing (13\%), pentose conversion (7\%), cellulose production (6\%) and power cycle $(3 \%)$. The progress ratio is derived by applying the cost improvement potentials per process step to the relative contribution of these steps to the overall investment costs, as presented in Table 1. This approach results in a scale-independent learning progress ratio in the range of $99 \%$ (Table 2).

\subsubsection{Lignocellulose to Fischer-Tropsch}

3.3.4.1. Process description. The process from biomass-toFischer-Tropsch (FT) diesel comprises of three major steps, (i) the pre-treatment of the raw feedstock, (ii) the gasification of lignocellulose material to syngas $\left(\mathrm{H}_{2}\right.$ and $\mathrm{CO}$ ) and (iii) the FT reactor where the syngas is used to synthesize FT (synthetic) diesel, although a multitude of end products can be synthesized, e.g. kerosene. Various process types exist (e.g. atmospheric or pressurized, air- or oxygen-blown), each with specific advantages and disadvantages [51]. The data used in this analysis [52,53], assume biomass pre-treatment through drying, 
Table 2 - Techno-economic overview for all biomass-to-biofuel technologies considered in this study.

Technology $^{\mathrm{a}}$

Unit

Amount

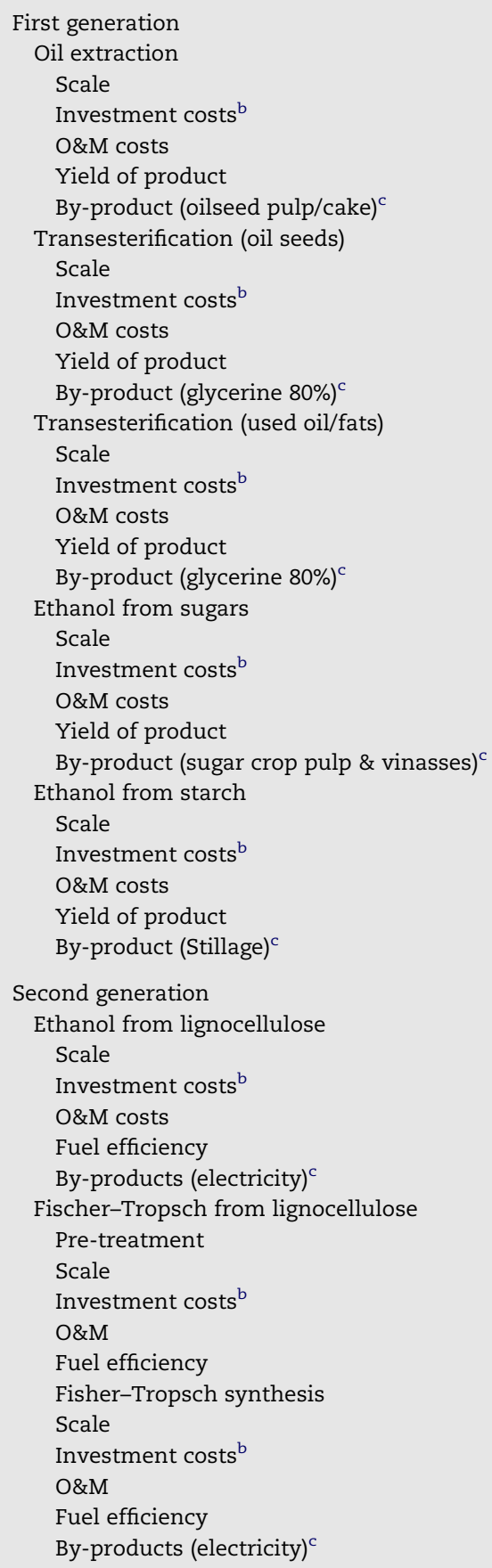

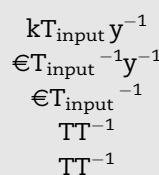

$\mathrm{kT}_{\text {input }} \mathrm{y}^{-1}$

$€ \mathrm{~T}_{\text {input }}{ }^{-1} \mathrm{y}^{-1}$

$€ \mathrm{~T}_{\text {input }}{ }^{-1}$

$\mathrm{TT}^{-1}$

$\mathrm{TT}^{-1}$
$\mathrm{kT}_{\text {input }} \mathrm{y}^{-1}$
$\in \mathrm{T}_{\text {input }}{ }^{-1} \mathrm{y}^{-1}$
$€ \mathrm{~T}_{\text {input }}{ }^{-1}$
$\mathrm{TT}^{-1}$
$\mathrm{TT}^{-1}$

$\mathrm{kT}_{\text {input }} \mathrm{y}^{-1}$

$€ \mathrm{~T}_{\text {input }}{ }^{-1} \mathrm{y}^{-1}$

$€ T_{\text {input }}{ }^{-1}$

$\mathrm{TT}^{-1}$

$\mathrm{TT}^{-1}$
$\mathrm{kT}_{\text {input }} \mathrm{y}^{-1}$
$€ \mathrm{~T}_{\text {input }}{ }^{-1} \mathrm{y}^{-1}$
$€ \mathrm{~T}_{\text {input }}{ }^{-1}$
$\mathrm{TT}^{-1}$
$\mathrm{TT}^{-1}$

$500\left(\sim 665 \mathrm{MW}_{\mathrm{th}}\right)$

103

27

0.39

0.59

$100\left(\sim 134 \mathrm{MW}_{\text {th }}\right)$

200

81

1.00

0.11

$50\left(\sim 67 \mathrm{MW}_{\text {th }}\right)$

300

89

1.00

0.10

$100\left(\sim 54 \mathrm{MW}_{\text {th }}\right)$

163

67

0.29

$0.31 \& 0.12$

$100\left(\sim 54 \mathrm{MW}_{\text {th }}\right)$

264

92

0.35

0.28

$\begin{array}{cl}\mathrm{MW}_{\text {th }} & 200 \\ \mathrm{M} € & 228 \\ \mathrm{M} \mathrm{y}^{-1} & 23 \\ \mathrm{GJ}_{\mathrm{EtoH}} \mathrm{GJ}_{\text {feedstock }}^{-1} & 0.39 \\ \mathrm{GJ}_{\text {electrcity }} \mathrm{GJ}_{\text {feedstock }}^{-1} & 0.105\end{array}$

$\mathrm{M} €$

$M € \mathrm{y}^{-1}$

30

9

$\mathrm{GJ}_{\text {treated feedstock }} \mathrm{GJ}_{\text {feedstock }}^{-1} \quad 0.95$

$\begin{array}{cl}M W_{\text {th }} & 200 \\ M € & 223 \\ M € \mathrm{y}^{-1} & 13 \\ \mathrm{GJ}_{\mathrm{FT}} \mathrm{GJ}_{\mathrm{f} \text { feedstock }}^{-1} & 0.53 \\ \mathrm{GJ}_{\text {electrcity }} \mathrm{GJ}_{\text {feedstock }}^{-1} & 0.033\end{array}$

a For all technologies a load factor of $8000 \mathrm{~h}$ and an economic lifetime of 20 years was assumed, except for the pre-treatment step for FischerTopsch where a lifetime of 10 year is assumed.

b All investment costs are corrected with an annuity following the specifications under ${ }^{a}$ with an interest rate of $6 \%$.

c Residual streams from the processes are assumed to be sold on the market to form a reimbursement to the overall production costs. The following market prices for residual streams are assumed: oilseed pulp/cake $63 €$ tonne $^{-1}$, glycerin (80\%) $120 €$ tonne $^{-1}$, sugar crop pulp and vinasses $75 €$ tonne $^{-1}$, stillage $105 €$ tonne $^{-1}$ and electricity $47.7 € \mathrm{MWh}^{-1}$.

torrefaction and pelletisation, followed by an oxygen-blown entrained-flow gasifier for syngas production. The resulting raw biosyngas is cooled, conditioned, cleaned from the impurities, and used for FT synthesis to produce $\mathrm{C}^{+}$liquid fuels.
3.3.4.2. Investment and $O \& M$ costs. Analysis is based on cost data [53] of recently realised or planned gas-to-liquids (GTL) projects. For the required biomass-to-liquids (BTL), assumptions have been made concerning process steps that have

Please cite this article in press as: de Wit M, et al., Competition between biofuels: Modeling technological learning and cost reductions over time, Biomass and Bioenergy (2009), doi:10.1016/j.biombioe.2009.07.012 
Table 3 - Market-driven and scale-driven learning parameters (BASE-case).

\begin{tabular}{|c|c|c|c|c|c|c|}
\hline \multirow[t]{2}{*}{ Technology } & \multicolumn{2}{|c|}{ Market-driven learning } & \multicolumn{4}{|c|}{ Scale-driven learning } \\
\hline & $\begin{array}{c}\text { Initial cum. } \\
\text { installed capacity } \\
2005\left[\mathrm{MW}_{\text {th }}\right]\end{array}$ & PR $[-]$ & Scale factor $[-]$ & $\begin{array}{c}\text { Maximum } \\
\text { scale2 }\left[\mathrm{MW}_{\text {th }}\right]\end{array}$ & $\begin{array}{c}\text { Maximum } \\
\text { market share [\%] }\end{array}$ & $\begin{array}{l}\text { Doubling } \\
\text { time [years] }\end{array}$ \\
\hline \multicolumn{7}{|l|}{ First generation } \\
\hline $\begin{array}{l}\text { Transesterification } \\
\text { (oil seeds and oils/fats) }\end{array}$ & $214.5(\mathrm{PJ})$ & $90 \%$ & n.a. & n.a. & n.a. & n.a. \\
\hline Sugar & 675 (PJ) & $80 \%$ & n.a. & n.a. & n.a. & n.a. \\
\hline Starch ethanol & 675 (PJ) & $80 \%$ & n.a. & n.a. & n.a. & n.a. \\
\hline \multicolumn{7}{|l|}{ Second generation } \\
\hline Lignocellulose & 200 & $99 \%$ & $0.7\left(\leq 1000 \mathrm{MW}_{\mathrm{th}}\right)$ & 3200 & 5 & 5 \\
\hline Ethanol & & & $0.85\left(>1000 \mathrm{MW}_{\mathrm{th}}\right)$ & & & \\
\hline Lignocellulose & 200 & $98 \%$ & $0.7\left(\leq 900 \mathrm{MW}_{\mathrm{th}}\right)$ & 3200 & 5 & 5 \\
\hline Fischer-Tropsch & & & $0.85\left(>900 \mathrm{MW}_{\mathrm{th}}\right)$ & & & \\
\hline
\end{tabular}

different capital costs for BTL compared to GTL. A costbreakdown is presented in Table 2 .

For scale-dependent costs, a scale-factor of 0.7 was used up until $900 \mathrm{MW}_{\text {th. }}$. The entrained-flow gasifier can be scaled-up to a size of several $\mathrm{GW}_{\text {th }}$ [53], but with increasing size, other parts of the installation (e.g. the pre-treatment and gas cleaning sections) have to be built in parallel, which diminish the overall scale effect [54-56]. Therefore, from $900 \mathrm{MW}_{\text {th }}$ onwards, a scale factor of 0.85 for overall investment costs was used. The maximum size was set at $3.2 \mathrm{GW}_{\text {th }}$ following the same reasoning as for advanced ethanol production. The scaling curve (presented in Fig. 3) and corresponding investment costs up to $3.2 \mathrm{GW}_{\text {th }}$ compares well to other studies $[54,56]$.

3.3.4.3. Scale-independent technological improvement and cost reductions prospects. Several technologies considered for FTproduction are not yet fully proven or commercially available: pressurized (oxygen-blown) gasifiers still need further development. A very critical step is gas cleaning, and it still has to be proven whether the (hot) gas cleaning section is able to meet strict cleaning requirements for reforming, shift and

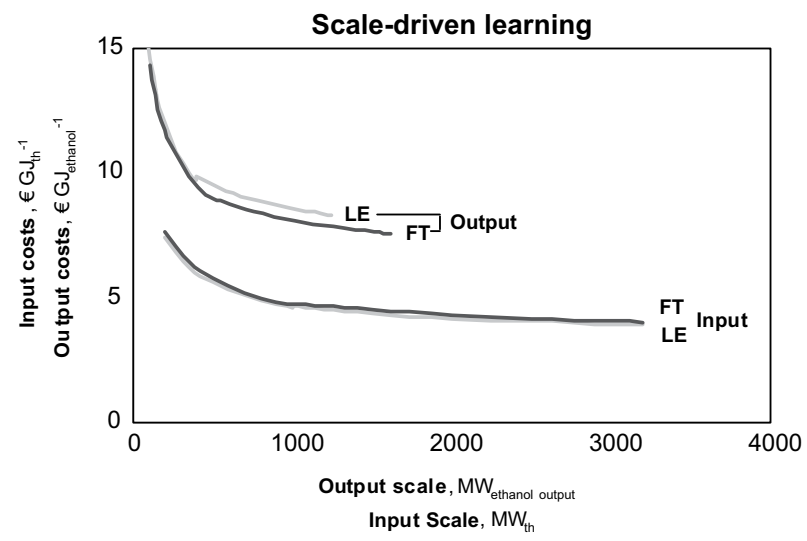

Fig. 3 - Scale-driven learning curve for the lignocelluloseto-ethanol (LE) and lignocellulose-to-Fischer-Tropsch (FT) conversion technology. synthesis. Another critical factor is the catalyst selectivity to increase $\mathrm{C}^{+}$output. Based on these possible technological improvements, a (relatively modest) progress ratio for scaleindependent learning was assumed in the range of $98 \%$ (see Table 2)

3.3.4.4. Scale-driven learning for lignocellulose ethanol and Fischer-Tropsch. Fig. 3 displays the scale-dependant learning curve for the conversion technologies LE and FT. The lower two curves represent the conversion costs in relation to the (thermal) feedstock input ( $\mathrm{MW}_{\text {th }}$ in) scale and conversion costs for feedstock input $\left(€(\text { GJfeed in })^{-1}\right)$. The two upper curves present the fuel production costs $(€(G) \text { fuel out })^{-1}$ ) for the respective fuel output scales (MWfuel out).

\section{Results and discussion}

This section presents the BASE-case model run (4.1) and the outcomes for the sensitivity analysis (4.2). Other BioTrans results are presented elsewhere in this volume [3,6].

\subsection{BioTrans output under BASE-case assumptions}

Under BASE-case assumptions (Table 4) biodiesel is the most cost effective fuel, completely dominating the market when only in competition with bioethanol (Fig. 5-a). The better cost performance of biodiesel over bioethanol is explained by lower feedstock costs for oil crops compared to sugar and starch crops and by relatively lower capital and operational expenses for transesterification of oil to biodiesel compared to (hydrolysis) and fermentation of sugar and starch crops to bioethanol. The initial production cost advantage and market domination of biodiesel blocks opportunities for bioethanol to learn and thereby to decrease costs.

Under the BASE-case assumptions both 2nd generation biofuel production routes are available for market introduction (when cost competitive) by 2010 . This, immediately upon availability, results in market introduction of FT in 2010 at costs of $19.3 € \mathrm{GJ}^{-1}$. Given the ambitious (target-driven) demand for biofuels high cost oil-crop resources are required 
Table 4 - Parameter variations as used in the sensitivity analysis.

\begin{tabular}{|c|c|c|c|}
\hline Subject/case & Parameter & Default value (BASE-case) & Case value \\
\hline \multicolumn{4}{|l|}{ Investment costs } \\
\hline Investment costs doubled & Investment costs & As presented in Table 2 & $\begin{array}{l}\text { Double the values as } \\
\text { presented in Table } 2\end{array}$ \\
\hline $20 \%$ lower 2 nd gen. investment costs & Investment costs & As presented in Table 2 & $\begin{array}{l}\text { Investment costs FT } \\
\text { and LE reduced by } 20 \%\end{array}$ \\
\hline \multicolumn{4}{|l|}{ Learning } \\
\hline Improved learning 2nd gen. & Progress ratios (PRs) & As presented in Table 3 & $\begin{array}{l}\text { All PRs set to } 1, \text { PRs for } \\
\text { FT and LE set to } 0,95\end{array}$ \\
\hline Slower up-scaling 2nd gen. & Doubling-time FT and LE & 5 & 10 \\
\hline \multicolumn{4}{|l|}{ Market introduction } \\
\hline Delayed availability FT & Year of market availability FT & 2010 & 2020 \\
\hline \multirow[t]{2}{*}{ Delayed FT + improved eff. LE } & Year of market availability FT & 2010 & 2020 \\
\hline & Fuel efficiency LE & 0.39 & 0.47 \\
\hline \multicolumn{4}{|l|}{ Subtarget } \\
\hline $\begin{array}{l}\text { Subtargets for gasoline and diesel } \\
\text { substitutes }\end{array}$ & $\begin{array}{l}\text { Subtargets gasoline and } \\
\text { diesel substitutes }\end{array}$ & No differentiation & $\begin{array}{l}20 \% \text { gasoline substitutes } \\
\text { and } 80 \% \text { diesel substitutes }\end{array}$ \\
\hline
\end{tabular}

to meet this supply. So, despite fairly high FT production costs, it competes with the most costly biodiesel immediately in 2010. From 2010 onwards, FT gradually increases its market share, to reach a $64 \%$ share by 2030 . The dominance of produced volumes FT over biodiesel until 2030 is driven by rapid cost reductions of both the feedstock and conversion costs for FT. Although FT is competitive with the most expensive biodiesel, on average overall FT costs are still higher then biodiesel costs (see Fig. 4-a). Note that absolute biodiesel volumes increase continuously.

LE does not enter the market due to higher initial (2010) production costs. As the BioTrans model uses a least cost optimization routine, no market introduction is reached. Also two other features of the model cause it to make 'radical' choices: the fact that the model is myopic (short-sighted) and because endogenous learning creates path-dependencies. These mechanisms are further discussed in Section 4.2.3.

\subsection{Sensitivity analysis}

Aim of the sensitivity analysis is (i) to explore how variations in parameter values affect the fuel production cost levels and their improvement potential over time, and (ii) what biofuel mix is obtained under a set of parameter values and how it relates to (and differs from) the baseline (BASE-case). Parameter values of four drivers, that impact on the market dynamics, are varied: (i) investment costs (ii) progress rates, both scale and experience learning, (iii) timing of market introduction of technologies and (iv) the existence of separate supply markets for diesel and gasoline substitutes, see Table 4

\subsubsection{Investment costs}

Investment and operation costs for all technologies considered in the modeling are subject to uncertainties. Most data used as basis for modeling originated from studies carried out between 2000 and 2004. However, since then surging (volatile) raw material prices, increased demand for power technologies (e.g. boilers and gas turbines) and a fluctuating Dollar-Euro exchange rate have impacted on the investment costs for power technologies. At the moment of writing, the global economic downturn (crisis) slows off demand thereby bringing prices back to moderate levels which could bring down investment costs in the near future. This all the more illustrates the need to investigate the implications of price fluctuations on market dynamics. Because the production of advanced biofuels is more material and therefore capital intensive than 1st generation biofuels, high prices provide a relative advantage for 1st generation biofuels.

Because of the multitude of drivers affecting production cost levels, a broad range was chosen to explore sensitivities. Two approaches were followed: (i) the effect of integral higher investment costs for all technologies, driven e.g. by increased steel prices, was explored. As a first order approach, investment costs for all technologies were doubled. (ii) A second case was explored in which investment costs for 2nd generation technologies were lowered by $20 \%$, compared to the BASE-case. This is in line with investment costs figures in literature, e.g. [34,57].Fig. 5-d displays the case where investment cost is doubled (invest cost double case). Two observations stand out in comparison with the BASE-case: (i) introduction of FT production is delayed until 2017, explained by a higher increase in conversion costs for 2nd compared to 1st generation biofuels. Overall FT production cost increases by $42 \%$ compared to biodiesel production by only $8 \%$, as seen in Fig. 4-d. (ii) The delayed FT introduction stimulates biodiesel production, up to and after 2017, mainly because the use of high-cost oil crop feedstocks remains cost competitive even longer. Fig. 5-c depicts the investment cost-20\% of 2nd generation case. Due to lower conversion costs FT production is more cost effective, to compete with biodiesel early on, hence expanding its share in the biofuel mix at the expense of biodiesel production, reaching a 78\% market share by 2030 .

Results show that an integral increase of investment costs strongly favours biodiesel production. Furthermore, because higher investment costs raise overall production costs, especially for 2 nd generation technologies, it weakens the relative competitiveness with fossil transport fuels (see Fig. 4-d). If, on 


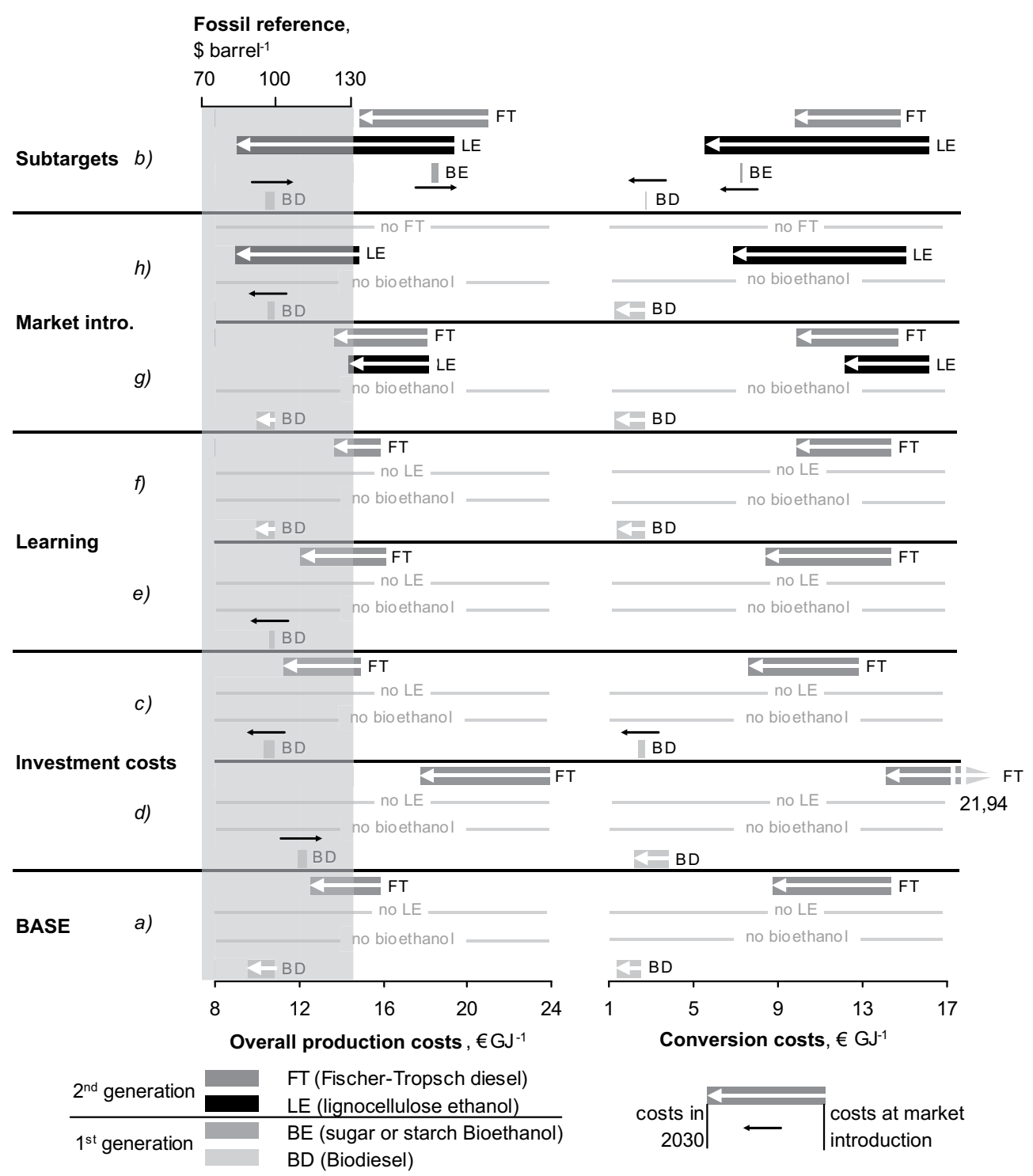

NOTE The fossil reference corresponds to $€ \mathrm{GJ}^{-1}$ following a $1.4 \$ €^{-1}$ exchange rate. Only crude oil prices - and no other processing costs - are considered.

Fig. 4 - Overview of the conversion costs and the overall production costs of biofuels under the BASE-case and cases explored in the sensitivity analysis.

the other hand, investment costs are reduced for 2nd generation technologies, the production cost gap with biodiesel can be closed earlier on, paving the way for accelerated implementation of FT production.

\subsubsection{Scale-driven and experience-driven learning}

First generation biofuel conversion technologies are not assumed to achieve any further substantial scale increases over time. For the extent that they do, resulting cost reductions are included in the experience-driven (endogenous) learning parameter. Advanced conversion technologies, on the other hand, are considered to increase in scale considerably over time. Under BASE-case assumptions scale doubling takes place every 5 years. To explore how differences in upscaling speed impact on the results the doubling-time is varied between 3 and 10 years.
Fig. 5-f depicts the slower up-scaling case where the doubling-time is set to 10 years. It can be seen that the effect on the moment of market introduction and the share in the biofuel mix of FT is hardly affected. The FT conversion costs, however, are affected as can be seen in Fig. 4-f. Also a faster up-scaling case was assessed, where the doubling time was set at 3 years. This case is not depicted since no significant changes were observed relative to the BASE. Fig. 5-e depicts the learning case where the progress ratio for both advanced technologies (LE and FT) was set at 0.95. Again, no significant change is observed. This is mainly due to the fact that the effect on cost reduction of up-scaling is much stronger than that of experience learning.

\subsubsection{Timing of market introduction}

The moment in time that advanced biofuel production routes will become (commercially) available is by definition 

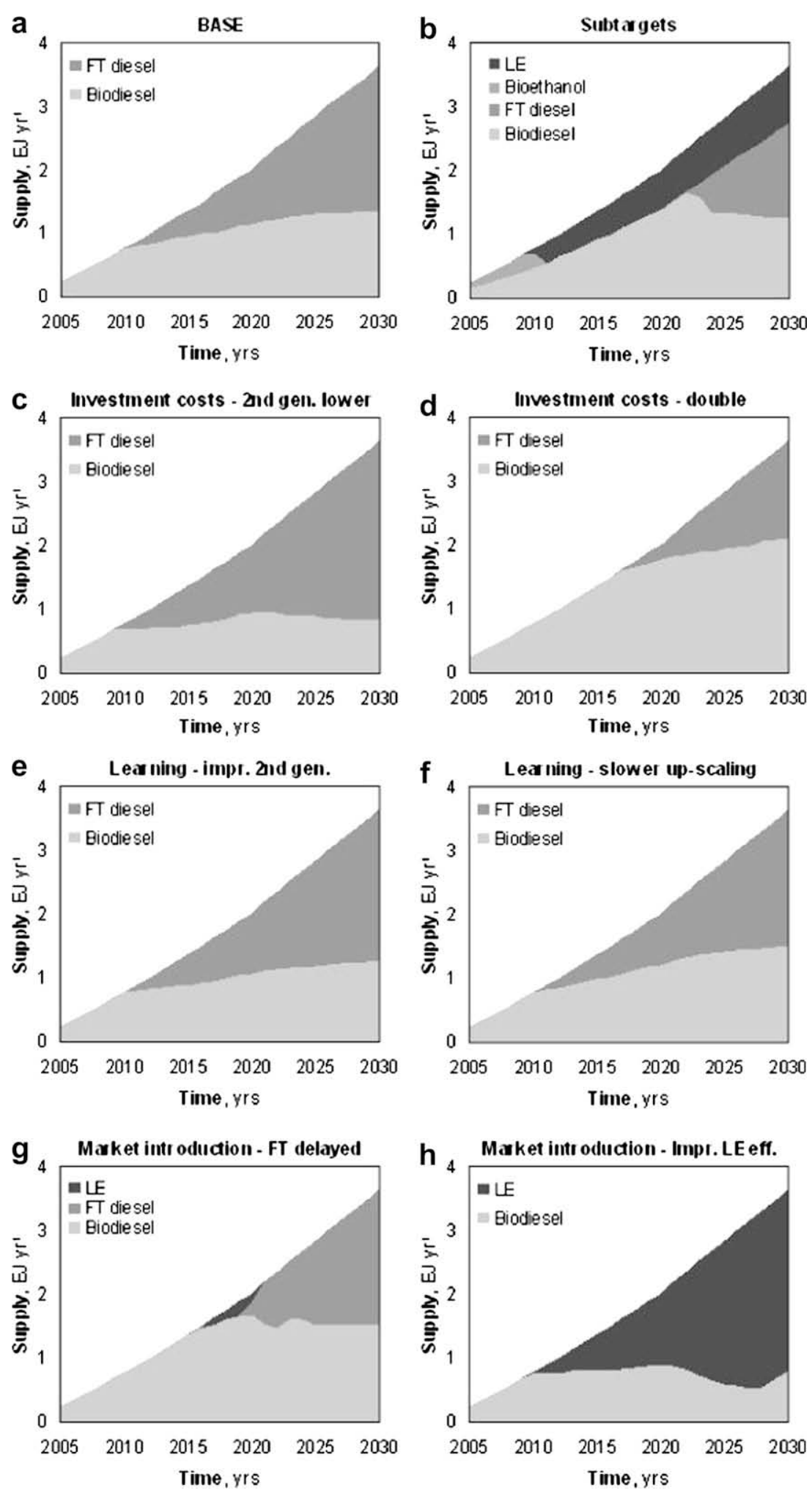

Fig. 5 - Biofuel mix for satisfying demand. Sensitivity analysis output for multiple parameter variations.

uncertain. The effect of a relative earlier market introduction of one technology relative to the other can seriously affect its share in the future biofuel mix. This is especially true if no separate gasoline and diesel substitute markets are present. In this case technologies can be considered to supply a homogenous product (there obviously is a difference between supplying 'a' biofuel versus supplying either a diesel or gasoline substitute as will be elaborated on in the next paragraph). 
When introduced in the market simultaneously, an initial fuel cost advantage will make the model to prefer one technology over the other causing only the preferred technology to penetrate the market (and thus let it learn and reduce costs); blocking the way for market introduction of the competing technology. This mechanism of lock-in is dominantly present in the BioTrans model due to its myopic foresight and least cost optimization criterion; leading to path-dependencies.

FT production is the preferred advanced biofuel option, due to a initial cost advantage, in the BASE-case. However, as discussed in Section 4.2.1, this is to some degree uncertain. To explore a scenario where LE enters the market before FT, two parameters are varied. Firstly, the market availability of FT is delayed to 2020. Secondly, the efficiency of LE is increased to $47 \%$ (in line with [34,46]), effectively stimulating both energy and cost performance. Fig. 5-g displays the earlier market intro 2nd ethanol case, where the market introduction of FT is delayed by 10 years. Three observations stand out compared to the BASE-case: (i) Due to high fuel costs for LE compared to 1st generation biodiesel, market introduction of lignocellulose ethanol is late (2016). (ii) This late market introduction and, subsequently, use of (more) high-cost oil crop feedstock results in significantly more biodiesel production to meet demand, up to and after 2016. (iii) Immediately upon the 'new' year of market availability for FT (2020) it makes a market entrance. This shows that (scale and non-scale related) learning of LE in the period from its market introduction to 2020 has not been sufficient to out-compete production costs for FT at its market introduction, even though both routes use the same feedstock base (at equal costs) to produce fuels. Fig. 5-h shows the case where the conversion efficiency for lignocellulose ethanol is raised from $39 \%$ (BASE-case) to $43 \%$ while maintaining late FT availability in 2020. With the improved efficiency lignocellulose ethanol now has an improved cost performance and is able to stay ahead of FT for the whole period. This illustrates the importance of the timing of market introduction; also for the long(er) term prospects for both technologies.

\subsubsection{Subtargets for biodiesel and bioethanol}

In the BASE-case and all other cases assessed so far, a single biofuel target is used (as is currently the case in the EU), i.e. no differentiation between subtargets for diesel and gasoline substitutes is assumed. For two reasons it is deemed appropriate to explore effects of a differentiated biofuel target for diesel and gasoline substitutes. Firstly, currently separate markets exist for transport fuels. Secondly, a differentiated target could create separate (niche) supply markets, thereby diversifying the production portfolio, increasing market resilience, spreading risk and preventing lock-in.

To evaluate which biofuel mix establishes under separate targets, the model is run with a constant $80-20 \%$ target, respectively for diesel and gasoline substitutes. All other parameter values are identical to the BASE-case. Fig. 5-b depicts this subtarget case. What stands out in this result is: (i) Starch and sugar based ethanol make it into the market only because of the target-driven demand for ethanol (as a gasoline substitute) and the unavailability of LE, until 2010. (ii) Directly upon commercial availability in 2010, LE enters and dominates the ethanol market share, due to a substantial production cost advantage compared to bioethanol (see
Fig. 4-b). (iii) For the diesel substitute market share, biodiesel is the most cost-competitive option even long after FT is available for market implementation. FT is only introduced into the market in 2022 compared to its immediate introduction in 2010 in the BASE-case. This observation is mainly explained by two mechanisms. Firstly, because the diesel substitute market is smaller in absolute terms, biodiesel production can rely on a relatively large low-cost feedstock potential. This makes biodiesel the preferred option for a longer period. Secondly, because LE is introduced into the market early, it starts using low-cost lignocellulose feedstocks (mainly forestry and agricultural residues) the same feedstock that FT production requires. Because with LE production lignocellulose feedstock becomes increasingly expensive, it adds to the delay of the $\mathrm{FT}$ route into the biofuel mix.

These results illustrate that regarding competition between bioethanol and LE, the latter is more cost effective directly upon availability of the technology. This in contrast to the competition between the two diesel substitutes where production costs are closer together.

\subsection{Methodological discussion and recommendations for further research}

\subsubsection{Modeling feedstock cost developments}

Developments in the production of (bioenergy) feedstocks were in this study modeled exogenously. The approach was significantly refined, compared to earlier efforts, by differentiating development speeds per crop. A next refinement step could be the modeling of feedstock cost development endogenously. This requires gaining insight into developments of the relation between historic production cost and cumulative produced volumes.

\subsubsection{No optimal path to a future optimal solution can be determined}

This is due to the myopic foresight and the model requirement to meet the increasing biofuel target each year based on the least-cost option(s). Moreover, several solutions may be near optimal, following different transition paths and arriving at different end solutions, to comparable costs [6].

\subsubsection{Prices versus costs and exchange rate fluctuations} Input data stem from a range of literature sources. Two cost data aspects introduce uncertainty (i) the difference between the use of costs versus prices and (ii) a changing euro-dollar exchange rate. Investment costs, presented in literature, can either relate to production costs but in some cases relate to (market) turnkey prices. Production costs reflect the (actual) expenses that arise from labour input, raw material use etc. Turnkey prices, on the other hand, also include margins for the value that is added along the supply chain. One reference [34] specifies the uncertainty range in (specific) investment and operation costs to be in the order of $\pm 30 \%$. Price data can be assumed to have even greater uncertainty. Cost and price data is mainly collected for the 2002-2006 period in either euros or (US) dollars. Given the strong (US dollar to euro) exchange rate fluctuations this introduces additional uncertainty. 


\subsubsection{Electricity reimbursement influences competition} between technologies

Both the advanced conversion technologies produce power and heat, mainly for system requirements. Depending on residual streams and process optimization, additional electricity (and heat) can be produced. With FT production, it is possible to optimize on fuel output, with only limited electricity output. The production of LE, on the other hand, produces considerable amounts of excess electricity, available from the non-fermentable lignin fraction. This electricity can potentially be delivered to the grid and thus form a reimbursement to overall fuel production costs. Although the influence of a varying electricity price - market price, reimbursement tariff or a combination - is not assessed in this analysis it may have a profound effect on the competition between technologies.

4.3.5. Standing capacity prevents radical technology switch BioTrans fills in the demand for biofuels every year with the least-cost option, without taking into account the standing production capacity. This can lead in theory to the situation where a technology is installed in one year and is substituted the next year by a (slightly) more cost-competitive option. In reality, the less cost-competitive option can, however, still be profitable (even more so than the more cost-competitive option) if investment cost has already been depreciated. Because production costs rather than profit (gained market price minus costs) is used for optimization, this effect is not included. Another driver to continue operation of a less cost effective (or profitable) technology is the fact that the investment has to be earned back. Retrofitting or upgrading older (depreciated) installations can be another option for reducing investment and operational costs, especially for 1st generation conversion technologies. While implementing this effect in future versions of BioTrans is recommended, in the current analysis we deem this issue of minor importance, as in none of the cases significant amounts of capacity (e.g. $>0.5 \mathrm{EJ} \mathrm{y}^{-1}$ ) are rapidly replaced.

\subsubsection{Separate gasoline and diesel substitute markets}

In the modeling, no distinction is made between markets for gasoline and diesel substitutes. On the one hand this reflects current European policy, not differentiating the biofuel target. On the other hand, at present separate transport fuel markets exist. Differentiated targets could stimulate diversification of feedstock and technology use and thereby, in an up-coming market, prevent lock-in of suboptimal options.

\section{General discussion, conclusions and policy implications}

Based on the model results, the following conclusions are drawn:

- The potential to reduce conversion installation costs between 2005 and 2030 is considerably larger for advanced biofuel options than for 1st generation biofuels. Key driver for reducing advanced biofuel conversion costs is up-scaling from pilot scale to 'full' industrial scale, in the BASE-case assumed to take approximately 20 years. Production cost reduction potential for 1st generation biofuels is limited.

- At moderate investment costs advanced biofuel options enter the market upon availability. With increasing investment costs for all technologies, e.g. steered by higher steel prices, 1st generation biofuels have a relative advantage, delaying the diffusion of advanced biofuels. Results suggest that this delay could range from several years up to a decade. Given the strong effect of changing investment costs on 2nd generation market penetration, potentially investment subsidies for 2nd generation biofuel plants could be an important prerequisite for a successful market introduction of advanced biofuels.

- Domestic European feedstock resources are relatively scarce at ambitious biofuel targets, which require the use of more expensive resources (produced on more expensive land or regions). Expenses for resources make up the majority of 1st generation biofuel costs. This stimulates the production for advanced biofuels in two ways (i) woody and grassy resources have a higher productivity and (ii) resource expenses are only a minor part of advanced fuel costs.

- In the competition for market diffusion, the relative moment of market implementation plays a key role. When a technology is implemented it can start up-scaling and gain operational experience, steadily decreasing production costs. When the period between the market penetration of two competing technologies prolongs, the chances for the last technology to be implemented diminish. Policy that aims at preventing lock-in should focus on facilitating opportunities to establish technology portfolios. One measure could be differentiation of a biofuel target for gasoline and diesel substitutes for advanced biofuels.

- Production cost levels for conventional crops and dedicated bioenergy crops have the potential to be considerably reduced, in the range of a 30\% reduction over 25 years. Feedstock production cost developments were modeled exogenously with crop-specific learning rates. This is a major refinement, compared to earlier modeling endeavors, which more adequately takes into account the different stages of development between crop production systems.

- The production of advanced biofuels is more material and therefore capital intensive than 1st generation biofuels. For this reason, fluctuating raw material (and other) prices impact on the competition between 1st and 2nd generation biofuels. Results indicate that high price levels provide a relative advantage to 1st generation biofuels and, vice versa, low price levels stimulate 2nd generation biofuels. Model outcomes show that a mere $20 \%$ decrease in 2 nd generation installation investment costs lead to a $50 \%$ market share already in 2020 (instead of 2025 in the BASE-case).

- Overall production costs for 1st and 2nd generation biofuels will, for most cases, be cost competitive with fossil transport fuels, in the range of 70-130 $\$$ barrel $^{-1}\left(7.8-14.5 € \mathrm{GJ}^{-1}\right)$ oil equivalent, by 2030 . First generation biodiesel shows stable overall production costs of around $100 \$$ barrel $^{-1}$. Advanced biofuel options start-off more expensive, in the 
range of $180 \$$ barrel $^{-1}\left(20 € \mathrm{GJ}^{-1}\right)$, but have opportunities to reduce costs significantly, $30-60 \%$, to become cost competitive with fossil transport fuels in the range of 70-130 \$ barrel $^{-1}\left(7.8-14.5 € \mathrm{GJ}^{-1}\right)$.

The modeling of production cost developments required different approaches for various biofuel options. The most challenging task was to adequately model advanced biofuel options, because of the limited availability of (historic) production costs data related to installed capacity. This challenge was satisfactory met by the developed approach (combining bottom-up and top-down insights). Even though, this approach demanded extensive bottom-up engineering data and adaptations to the modeling routine. Furthermore, the inclusion of several parameters (e.g. progress ratios, scaling laws, time of market introduction etc.) in the sensitivity analysis allowed for an exploration of their individual impact on cost developments and market diffusion.

\section{Acknowledgements}

This study is conducted as part of the REFUEL project funded by the European Commission under the Intelligent Energy Europe programme. The authors wish to acknowledge the help of several colleagues. Ewout Deurwaarder, as part of the research team, for laying part of the fundament for this analysis in the earlier VIEWLS study, his efforts in compiling input data and sharing his in-depth knowledge of the systems analysed. Jarno Kuijvenhoven and Bram van der Drift, for sharing their expert knowledge during a meeting. Oscar van Vliet, for providing data and literature. Joost van Stralen, for his help with some technicalities of the BioTrans model. The anonymous reviewers are thanked for their comprehensive comments and suggestions.

\section{R E F E R E N C E S}

[1] Commission of the European Communities. The renewable energy progress report: commission report in accordance with Article 3 of Directive 2001/77/EC, Article 4(2) of Directive 2003/30/EC and on the implementation of the EU biomass action plan. $\operatorname{COM}(2005) 628 ; 2009$.

[2] EurObserv'ER. Biofuels barometer.

[3] Londo M, Lensink S, Wakker A, Fischer G, Prieler S, Van Velthuizen $\mathrm{H}$, et al. The REFUEL EU road map for biofuels in transport: application of the project's tools to some short-term policy issues. Biomasand Bioenergy, in press.

[4] Junginger M, Lako P, Lensink S, Sark Wv, Weiss M. Technological learning in the energy sector. Netherlands Environmental Assessment Agency (PBL); 2008. p. 192.

[5] Banse M. EU Biofuel policy and effects on production and trade: first modeling results with ESIM and GTAP. Agricultural Economics Research Institute (LEI); 2007.

[6] Lensink S, Londo M. Assessment of biofuels supporting policies using the biotrans model. Biomass and Bioenergy, in press.

[7] Bantz SG, Deaton ML. Understanding U.S. biodiesel industry growth using system dynamics modeling; 2006. Paper presented at the 2006 IEEE Systems and information engineering design symposium, April 28, 2006, University of Virginia, USA.
[8] van den Wall Bake JD, Junginger M, Faaij A, Poot T, Walter A. Explaining the experience curve: cost reductions of Brazilian ethanol from sugarcane. Biomass and Bioenergy 2009;33(4): 644-58.

[9] Hettinga WG, Junginger HM, Dekker SC, Hoogwijk M, McAloon AJ, Hicks KB. Understanding the reductions in US corn ethanol production costs: An experience curve approach. Energy Policy, in Press.

[10] Berghout NA. Technological learning in the german biodiesel industry: an experience curve approach to quantify reductions in production costs, energy use and greenhouse gas emissions. Utrecht University, Copernicus Institute, The Netherlands, 2008.

[11] Ewert F, Rounsevell MDA, Reginster I, Metzger MJ, Leemans R. Future scenarios of European agricultural land use: I. Estimating changes in crop productivity. Agriculture, Ecosystems \& Environment 2005;107(2-3):101-16.

[12] Calderini DF, Slafer GA. Changes in yield and yield stability in wheat during the 20th century. Field Crops Research 1998; 57(3):335-47.

[13] Evans LT, Wallace JS, Beavington F. Adapting and improving crops: the endless task philosophical transactions. Biological Sciences 1997;352(1356):901-6.

[14] De Wit MP, Faaij A. European biomass resources potential and costs. Biomass and Bioenergy 2009;34, doi:10.1016/j. biombioe.2009.07.011.

[15] Campinhos E. Sustainable plantations of high yield Eucalytus trees for prodcution of fiber: the Aracruz case. New Forests 1999;17(1-3):129-43.

[16] Mercer D, Underwood A. Australian timber plantations: national vision, local response. Land Use Policy 2002;19(2):107-22.

[17] Mola-Yudego B, Aronsson P. Yield models for commercial willow biomass plantations in Sweden. Biomass and Bioenergy 2008;32(9):829-37.

[18] Van Hulst KS. Willow for energy use in Poland: a road map for the development of large scale, short-rotation willow production and energy use in Poland. Copernicus Institute, Utrecht University; 2007. p. 146.

[19] Rosenqvist H, Borjesson P, Berndes G, Neij L. The prospects of cost reductions in willow production. In: 14th European biomass conference; 2005.

[20] Wyman CE. Biomass ethanol: technological progress, opportunities, and commercial challenges. Annual Review of Energy and the Environment 1999;24:189-226.

[21] Boston Consultancy Group (BCG). Perspectives on experience. Boston Consultancy Group Inc; 1968.

[22] Junginger M, de Visser E, Hjort-Gregersen K, Koornneef J, Raven R, Faaij A, et al. Technological learning in bioenergy systems. Energy Policy 2006;34(18):4024-41.

[23] CHOREN. CHOREN: decision falls in favour of Schwedt, press release 18 december 2007.

[24] USDOE. DOE selects six cellulosic ethanol plants or up to $\$ 385$ million in federal funding, press release 28 February 2007.

[25] Faaij A, Meuleman B, Ree Rv. Long term perspectives of biomass integrated/combined cycle (BIG/CC) technology; costs and electrical efficiency. Department of Science, Technology and Society; 1999. p. 102.

[26] Uyterlinde MA, Junginger M, de Vries HJ, Faaij APC, Turkenburg WC. Implications of technological learning on the prospects for renewable energy technologies in Europe. Energy Policy 2007;35(8):4072-87.

[27] Blok K. Introduction to energy analysis. Amsterdam: Techne Press; 2006. p. 256.

[28] Haldi J, Whitcomb D. Economies of scale in industrial plants. The Journal of Political Economy 1967;75(4):373-85.

[29] Nguyen MH, Prince RGH. A simple rule for bioenergy conversion plant size optimisation: bioethanol from sugar cane and sweet sorghum. Biomass and Bioenergy 1996;10(5-6):361-5. 
[30] Grübler A. Technology and global change. Cambridge, United Kingdom: Cambridge University Press; 1998. p. 452.

[31] Watson WJ. Constructing success in the electric power industry: combined cycle gas turbines and fluidized beds. University of Sussex; 1997. p. 439.

[32] Junginger M, Faaij A, Turkenburg WC. Global experience curves for wind farms. Energy Policy 2005;33(2):133-50.

[33] Koornneef J, Junginger M, Faaij A. Development of fluidized bed combustion-an overview of trends, performance and cost. Progress in Energy and Combustion Science 2007;33(1): 19-55.

[34] Hamelinck CN, Hooijdonk Gv, Faaij APC. Ethanol from lignocellulosic biomass: techno-economic performance in short-, middle- and long-term. Biomass and Bioenergy 2005; 28(4):384-410.

[35] FAO, FAOSTAT - agriculture, in FOASTAT-agriculture; 2006 as read on, e.g., February 2007.

[36] Smeets EMW, Lewandowski IM, Faaij APC. The economical and environmental performance of Miscanthus and switchgrass production and supply chains in a European setting. Renewable and Sustainable Energy Reviews 2009; 13(6-7):1230-45.

[37] Körbitz W, Berger C, Waginger E, Wörgetter M. Best case studies on biodiesel production plants in Europe. IEA Bioenergy task; 2004. p. 39.

[38] Schöpe M, Britschkat G. Macreconomic evaluation of rape cultivation for biodiesel production in Germany. IFO; 2002.

[39] EUobserver; 2006

[40] Lichts FO. Ethanol production costs: a worldwide survey. FO Lights special report no. 132.

[41] Mortimer ND, Elsayed MA, Horne RE. Energy and greenhouse gas emissions for bioethanol production from wheat grain and sugar beet. Report by Sheffield Hallam University for Britisch Sugar.

[42] United Nations, Industry statistics: commodity production statistics; 2007.

[43] Miguel Rd. Outlook for bioethanol in Europe, boosting consumption. presentation by the European Bioethanol Fuel Association, Seville, Spain; 2006

[44] Mosier N, Wyman C, Dale B, Elander R, Lee YY, Holtzapple M, et al. Features of promising technologies for pretreatment of lignocellulosic biomass. Bioresource Technology 2005;96(6): 673-86.

[45] Lynd LR; 1996.

[46] Lynd LR, Zyl WHV, McBride JE, Laser M. Consolidated bioprocessing of cellulosic biomass: an update. Current Opinion in Biotechnology 2005;16(5):577-83.

[47] Froese RE, Waterstraut JR, Johnson DM, Shonnard DR, Whitmarsh JH, Miller CA. Lignocellulosic ethanol: is it economically and financially viable as a fuel source? Environmental Quality Management 2008;18(1):23-45.

[48] Kuijvenhoven JF. Process design for an integral (ligno-) Cellulose to bio-ethanol production plant, TUDelft, Final report, confidential.

[49] Reith JH, de Bont JMA. Co-production of bioethanol, lactic acid, electricity and heat from lignocellulosic biomass. SenterNovem. p. 40.

[50] Hahn-Hägerdahl B, Karhumaa K, Fonseca C, SpencerMartins I, Gorwa-Grauslund M. Towards industrial pentosefermenting yeast strains. Applied Microbiology and Biotechnology 2007;74(5):937-53.

[51] Hamelinck CN, Faaij APC. Future prospects for production of methanol and hydrogen from biomass. Utrecht University, Department of Science, Technology and Society; 2002. p. 32 [+annexes].

[52] Bergman PCA, Boersma RR, Zwart RWR, Kiel JHA. Torrefaction for biomass co-firing in existing coal fired power stations. Energy research Centre of the Netherlands; 2005.

[53] Boerrigter H. Economy of Biomass-to-Liquids (BTL) plants: an engineering assessment. Energy reseach Centre of the Netherlands (ECN), unit Biomass, Coal \& Environmental research; 2006. p. 29.

[54] Hamelinck CN, Faaij APC, den Uil H, Boerrigter H. Production of FT transportation fuels from biomass; technical options, process analysis and optimisation, and development potential. Energy 2004;29(11):1743-71.

[55] Tijmensen MJA, Faaij APC, Hamelinck CN, van Hardeveld MRM. Exploration of the possibilities for production of Fischer Tropsch liquids and power via biomass gasification. Biomass and Bioenergy 2002;23(2):129-52.

[56] van Vliet OPR, Faaij APC, Turkenburg WC. Fischer-Tropsch diesel production in a well-to-wheel perspective: A carbon, energy flow and cost analysis. Energy Conversion and Management 2009;50(4):855-76.

[57] Aden A, Ruth M, Ibsen K, Jechura J, Neeves K, Sheehan J, et al. Lignocellulosic biomass to ethanol process design and economics utilizing co-current dilute acid prehydrolysis and enzymatic hydrolysis for corn stover. National Renewable Energy Laboratory. p. 154.

[58] Gumeniuk A. The agro-environmental analysis of using energy plants in Poland: willow, virginia mallow and miscanthus. Warsaw University; 2005.

[59] Ledin S. Willow wood properties, production and economy. Biomass and Bioenergy 1996;11(2-3):75-83.

[60] Rosenqvist H, Borjesson P, Berndes G, Neij L. The prospects of cost reductions in willow production. In: Proceedings of the 14th European biomass conference; 2005.

[61] Szczukowski S. Wierzba energetyczna. plantpress. 